\title{
FAST OBJECT DETECTION IN DIGITAL GRAYSCALE IMAGES
}

\author{
Aivars Lorencs, Ints Mednieks, and Juris Siṇica-Siṇavskis \\ Institute of Electronics and Computer Science, Dzērbenes iela 14, Rīga, LV-1006, LATVIA \\ E-mail: jss@edi.Iv
}

Communicated by Ivars Biḷinskis

\begin{abstract}
The problem of specific object detection in digital grayscale images is considered under the following conditions: relatively small image fragments can be analysed (a priori information about the size of objects is available); images contain a varying undefined background (clutter) of larger objects; processing time should be minimised and must be independent from the image contents; proposed methods should provide for efficient implementation in application-specific electronic circuits. The last two conditions reflect the aim to propose approaches suitable for application in real time systems where known sophisticated methods would be inapplicable. The research is motivated by potential applications in the food industry (detection of contaminants in products from their X-ray images), medicine (detection of anomalies in fragments of computer tomography images etc.). Possible objects to be detected may include compact small objects, curved lines in different directions, and small regions of pixels with brightness different from the background. The paper describes proposed image processing approaches to detection of such objects and the results obtained from processing of sample food images.
\end{abstract}

Key words: digital image processing, object detection, feature detection.

\section{INTRODUCTION}

Various formal methods have been developed for automated pattern recognition and classification. A wide spectrum of deterministic and statistic, analytic and structural (synthetic), training-based and conservative methods are described in (Tou and Gonzales, 1974; Fukunaga, 1990; Pratt, 2001).

Applicability of the particular method is largely determined by the form of information representing the category of real scenes to be analysed. If this information is mainly of stochastic nature, classification rules must be based on statistics. However, this does not mean that the decision rules will be statistic; in all cases they will be formulated deterministically and, by chance, may lead to wrong decisions.

In this work we propose object detection methods based on the assumption that scenes under consideration are represented by digital images formed from matrices $\mathbf{A}=\left(a_{i j}\right)$ of rational numbers. At the same time it is assumed that acquisition of digital images can be influenced by random factors that introduce additive Gaussian noise with zero mean and a definite variance. As a result, two images obtained from the same object in the same conditions may differ. Excellent description of analysis methods of such phenomena is given in Armitage et al. (2001).

Detection of small objects over some background clutter is an image processing topic that has been the focus of many researchers, e.g. dealing with detection of moving objects, targeting applications in astronomy and radar technology (Deshpande et al., 1999; Warren, 2002; Liu et al., 2005). A lot of techniques for detecting small moving targets exploiting both temporal and spatial filtering were developed, mainly for military applications (Warren, 2002). Recent advances in solving this task also include learning-based techniques that are capable of adapting to changing background and characteristics of the objects to be detected (Warren, 2002; Liu et al., 2005). In our case, detection should be performed on the basis of a single image. However, similar spatial filtering approaches to separation of small objects can be used. For example, application of a median subtraction filter (Warren, 2002; Liu et al., 2005), max-mean filter, max-median filter (Liu et al., 2005), morphological filters (Warren, 2002) may be useful and proposed for preprocessing of the images.

The aim of our paper is to propose image processing methods for detection of small objects in grayscale images that can be used for the development of systems operating in real time mode.

\section{METHODS}

Image preprocessing. For the considered analysis cases of digital images, objects to be detected can be located in different places of the background clutter. To use statistical methods of object detection, it is crucial that objects are 
represented with the equal magnitude in pixel values regardless of the background. Quite often, compensation for non-linear response of the imaging system is required to obtain such property. This can be achieved by applying a certain function to correct the measured pixel values $\hat{a}_{i j}$ and obtain the corrected ones $a_{i j}^{\prime}$, i.e. $a_{i j}^{\prime}=f\left(\hat{a}_{i j}\right)$. Correction function $f$ could be known in advance (related to properties of the imaging system) or derived experimentally by processing an image of the object with linearly changing thickness. In the former case, it can be rather complicated for calculations in real time; in the latter, its analytic approximation could be difficult to find. Therefore, we propose to use a look-up table approach where corrected values for all possible input pixel values are calculated in advance and saved in a table. During actual processing, corrected values for each pixel are obtained from this table by simple indexing. For digital images, the size of this table depends on the resolution of the analogue-to-digital converters (ADC) used to acquire the image.

The idea behind most of the methods for detecting small objects is to estimate the background image $\mathbf{G}$ and subtract it from the initial (corrected) image $\mathbf{A}^{\prime}$. Pixel values in resulting image $\mathbf{H}=\mathbf{A}^{\prime}-\mathbf{G}$ are centred around zero and small objects are emphasised. Taking into account the timing restrictions, we focused on simple approaches of background compensation, namely median subtraction, max-mean, max-median and morphological filters. It should be mentioned that, if the properties of background clutter are not limited, there will always be a chance to have a clutter that can not be distinguished from the small foreign object; both false positive and false negative detection errors may be obtained with certain probabilities. Specification of the application task should quantify these probabilities. A priori knowledge of the properties of background and objects to be detected can be used to choose the proper spatial filtering method.

The preprocessing approaches described above are used in the first stage of all proposed object detection methods.

Thresholding with connectivity analysis. The simplest approach that can be applied after the object extraction from the background is thresholding. If the signal-to-noise ratio is high enough, image pixels related to extracted objects have smaller brightness values than the pixels related to the background. Using a certain brightness threshold $t$, the binary image $\boldsymbol{B}$ is obtained with elements $b_{i j}=\left\{\begin{array}{l}1, \text { if } h_{i j}<t \\ 0, \text { if } h_{i j} \geq t\end{array}\right.$

where 1 's testify the presence of the sought objects. In the simplest case, the presence of a single pixel $b_{i j}$ with value 1 may result in a positive decision (object is found). However, due to the additive noise in pixel values related to the physical process of obtaining the image, accidental false positive decisions can be made. To lower the possibility of such errors, pixel connectivity analysis can be used after thresholding, based on ideas of mathematical morphology (Pratt, 2001).
The procedure of choosing the threshold is not defined to an end, however, selection of the threshold for this method can be performed in two ways depending on the noise level in pixel values of the initial image: 1) by processing the images of test samples without foreign objects. In this case, the threshold is set to a value less than the minimum pixel value obtained within all filtered images. Such an approach can by used if the noise spikes in pixel values of the filtered images are not lower than values related to the sought objects, so that the latter can be reliably separated by thresholding; 2) by processing the images of test samples with sought objects. Here, the threshold is set to a value that reliably allows to detect pixels related to sought objects. This is used in situations with higher noise levels when some of the pixel values in the filtered image related to noise are lower than values related to sought objects. In this case, the binary image may contain quite a lot of 1's related to noise so that connectivity analysis should be carefully performed to remove those. To perform this, a structuring element (SE) is defined corresponding to the sought shape of the object. SE is a small binary image containing 1's in pixels belonging to the defined shape and 0's in other pixels. To perform analysis of the thresholding result, SE is applied to the neighbourhood of each pixel of the binary image and decision about the presence of the sought object is made by counting the number of pixels that are 1 's both in the SE and pixel neighbourhood. If a sufficient number of such pixels are found, the object is said to be found.

Object detection based on covariance properties. For detection of small objects based on calculation of statistical features it is feasible to process images by fragments with size related to size of objects to be detected. Fragment size and overlapping of fragments should be chosen such that there is always a fragment containing the sought foreign object in full. The simplest approach is to set a fragment size $S$ twice as large as maximum size of the sought object in pixels $S_{0}$ and use overlapping of fragments by $S_{0}$ pixels on both axes.

The simplest statistical characteristics, namely mean value and variance, can be used to reveal the presence of a foreign object in a fragment of filtered image $\mathbf{H}$. However, such characteristics are not informative enough in low signal-to-noise ratio cases when the pixel values due to measurement noise may be comparable in magnitude to values related to foreign objects. The objects to be detected are characterised by low values of several neighbouring pixels that are perceived also by humans as an indicator of presence of some object in the image. Mathematically, such an indication can be given by a higher correlation between the neighbouring pixel values, which is not observed in case of a noise image.

Let us consider a task of detecting the presence of thin fishbones in a X-ray image of a fish fillet. For detecting the vertical segments of fishbones, it is proposed to calculate coefficients revealing covariance between the values of neighbouring pixels of several adjacent rows: 
$c_{r 0}=\sum_{i=1}^{S-Q} \sum_{j=1}^{S-Q} h_{i j} h_{(i+r), j}, \quad r=\overline{1, Q}$,

where $Q$ is the maximum distance in rows for which the covariance is analysed, and the summary covariance property $C_{Q}^{1}=\sum_{r=1}^{Q} c_{r 0}$ can be used to characterise covariance between vertically oriented neighbouring pixels in distances up to $Q$ rows. Such covariance properties can be also defined for detection of thin object segments oriented in other possible directions and results combined for solving the general detection task of such objects regardless of their orientation in the image.

Threshold $t$ can be chosen on the basis of processing $K$ images $\mathbf{H}_{k}^{0}, k=\overline{1, K}$ for which it is known in advance that they do not contain any fishbone objects, e.g. it can be set to value $t=\alpha \max \left(C_{Q}^{1}\right)$, where $\alpha$ is a chosen sensitivity parameter with value $\alpha>1$. The value of $\alpha$ can be close to 1 (e.g. $\alpha=1.1)$ if the sufficient number of images without fishbones are processed to obtain coefficients $C_{Q}^{1}$.

Different covariance-based properties can be defined to detect objects of different size and shape. For example, for the detection of small square objects of maximum size 2 pixels, coefficients revealing covariance of neighbouring pixels with distance 1 in all directions could be used. In such a way, the proposed approach is adjustable to the application task.

Calculation of only several coefficients related to covariance properties of the image and specific to the application task is needed to perform detection. In addition, this involves only calculation of dot products of elements of matrix that can be effectively implemented with modern processors. Therefore, the proposed approach can be effectively implemented for real-time operation.

Regression method. The regression method (RM) presented in this work is based on the same assumption that lays in the background of many pattern recognition methods, except for so called statistical recognition of universes (Pratt, 2001). To apply the regression method, it is necessary that scenes of the analysed category can be divided into a finite set of classes. This results in division of digital images into the same number of classes $K_{1}, \ldots, K_{a}$ so that $K_{s} \cap K_{t}=\varnothing$ for all $s \neq t$. Of course, there may not be a case where a digital image of a scene is related to none of the classes $K_{i}$.

Finally, it is assumed that a sufficient number of images from each class are available for investigation. This condition is necessary to fulfil in order to form an efficient system of rules for classification of images to be used in practice. Some ideas of the regression method are found in (Лоренц, 1984; 1989).

Forming the linear regression model involves several mathematical problems yet to be satisfactorily solved in future.
The first and major one is formulation of an adequate regression hypothesis. The regression model is based on the assumption that we can formulate such a hypothesis for the unknown function of $p$ variables $f\left(x_{1}, \ldots, x_{p}\right)=E Y_{\mathbf{x}}, \mathbf{x} \in D=$ $\left[a_{1}, b_{1}\right] \times \ldots \times\left[a_{p}, b_{p}\right]$, i.e. we can present an analytically explicit function $\breve{\chi}(\mathbf{x} ; \boldsymbol{\theta})$, for which a parameter vector $\boldsymbol{\theta}^{*}$ exists ensuring that the condition

$\forall \mathbf{x}\left[(\mathbf{x} \in D) \rightarrow\left(f(\mathbf{x})=\breve{\chi}\left(\mathbf{x} ; \boldsymbol{\theta}^{*}\right)\right)\right]$

is met.

In practical tasks there is not enough information available about the function $f$ to find function $\chi$. Usually we know only sample values of a random quantity $Y_{\mathbf{x}}$ corresponding to the values $y_{\mathbf{x}}$ of controlled variables $\mathbf{x}$ in a finite set $\mathrm{B}=$ $\left\{\mathbf{x}^{1}, \mathbf{x}^{2}, \ldots, \mathbf{x}^{\mathrm{r}}\right\}$. Obviously, these sample values are not values of the function $f$ in points $\mathbf{x}^{1}, \mathbf{x}^{2}, \ldots, \mathbf{x}^{\mathrm{r}}$ but, instead, they are realisations of random variables $Y_{i}=f\left(\mathbf{x}^{i}\right)+X_{i}$, where $X_{i}$ is independent random values with Gaussian distribution with mean $E X_{i}=0$ and variance $D X_{i}=\sigma^{2}$. Therefore, we can formulate only adequate hypothesis instead of a correct one, i.e. we can present an analytically explicit function $\breve{\chi}(\mathbf{x} ; \boldsymbol{\theta})$ for which a parameter vector $\boldsymbol{\theta}^{*}$ exists ensuring that the condition

$$
\sum_{i=1}^{r}\left(y_{i}-\breve{\chi}\left(\mathbf{x}^{i} ; \boldsymbol{\theta}^{*}\right)\right)^{2}<\delta
$$

is met for a small enough $\delta>0$. If the dimension of the parameter vector $\boldsymbol{\theta}$ is $r$, and $f$ is the function of one argument defined in segment $[a, b]$, then for arbitrary $\delta$ this condition will be met by the Lagrange interpolation polynomial $L_{r}(x)$ that is constructed for the set of values $\left\{y_{x^{1}}, y_{x^{2}}, \ldots, y_{x^{r}}\right\}$.

We are interested in limiting the dimension of vector $\theta$ by some fixed natural number $n$. Therefore, it would be important to know that, having a linear regression hypothesis, we can ensure sufficiently precise approximation of function $f$ in all $r$ points using a relatively small number of functions. Of course, our real goal would be to ensure a "good" approximation of function $f$ in all points of the controlled variables $\mathbf{x} \in D$. But today's results of mathematical investigations do not propose a solution of this problem if the knowledge about the function $f$ is limited by knowing that it is a continuous function defined in region $D$, for which we can determine real numbers $m$ and $M$, such that $m \leq f(\mathbf{x}) \leq$ $M$. The situation is not "improved" by knowing results of realisations $y_{\mathbf{x}}$ in certain points of the controlled variables. If $f$ is a continuous function defined in segment $[a, b]$ and its values are known in $r$ points $x^{1}, x^{2}, \ldots, x^{r}$, then the interpolation polynomial $L_{r}(x)$ approximates $f$ with accuracy given by

$\sup _{x \in[a, b]}\left|f(x)-L_{r}(x)\right| \leq \frac{\sup _{x \in[a, b]}\left|f^{r}(x)\right| \cdot \sup \left|\prod_{i=1}^{r}\left(x-x^{i}\right)\right|}{r !}$ 
(Бахвалов, 2001). Therefore, for the estimation of approximation accuracy, it is necessary to know the $r$-th derivative of the function $f$ that is impossible in practice.

As, generally speaking, $y_{i} \neq f\left(\mathbf{x}^{i}\right)$ but $E Y_{\mathbf{x}^{i}}=f\left(\mathbf{x}^{i}\right)$, then the reasonable way out from the situation is found in such a way: find a parametric function $\breve{\chi}(\mathbf{x} ; \boldsymbol{\theta})$ providing "good" approximation of function $f(\mathbf{x})$ in the whole region $D$ using some value $\boldsymbol{\theta}^{*}$ of the parameter vector $\boldsymbol{\theta}$, and estimates $\hat{\boldsymbol{\theta}}$ of the unknown $\theta^{*}$ are sought providing the minimum of the function

$Q(\boldsymbol{\theta})=\sum_{i=1}^{r}\left(y_{i}-\breve{\chi}\left(\mathbf{x}^{i} ; \boldsymbol{\theta}\right)\right)^{2}$.

To find the appropriate function $\breve{\chi}(\mathbf{x} ; \boldsymbol{\theta})$, complete systems $\left[\varphi_{n}(\mathbf{x})\right]$ of orthogonal, resp. orthonormal functions defined in region $D$ can be used.

If $f(\mathbf{x})$ is a continuous function defined in region $D$, and $\left[\varphi_{n}(\mathbf{x})\right]$ is a system of orthogonal functions defined in region $D$ with a weighing function $p(\mathbf{x})>0$, then, in case of complete $\left[\varphi_{n}(\mathbf{x})\right]$ :

$\lim _{n \rightarrow \infty} \int_{D} p(\mathbf{x})\left(f(\mathbf{x})-s_{n}(\mathbf{x})\right)^{2} d(\mathbf{x})=0$

where $s_{n}(\mathbf{x})=\sum_{j=0}^{n} c_{j} \varphi_{j}(\mathbf{x}), c_{j}=\int_{D} p(\mathbf{x}) f(\mathbf{x}) \varphi_{j}(\mathbf{x}) d(\mathbf{x})=0$.

In the case of one variable, when $D=[-1,1]$, the Legendre, Chebyshev and Jacobi polynomials can be used as $\left[\varphi_{n}(\mathbf{x})\right]$. If $D=[-\pi, \pi]$, complete orthogonal system of functions is formed from the series of functions: $1, \cos x, \sin x, \cos 2 x$, $\sin 2 x, \ldots, \cos n x, \sin n x, \ldots$. It is proved (Курант и Гильберт, 1951) that, using a suitable construction from the system of functions $\left[f_{n}(x)\right]$ of one argument defined in segment $[a, b]$, it is possible to form a complete system of functions $\left[\varphi_{n}(\mathbf{x})\right]$ of $p$ variables defined in region $D$. Obviously, if $p(\mathbf{x}) \geq c>0$, then from the equation (6) it directly follows that $\lim _{n \rightarrow \infty} \int_{D}\left(f(\mathbf{x})-s_{n}(\mathbf{x})\right)^{2} d(\mathbf{x})=0$.

It means that the linear combination of functions $\varphi_{n}(\mathbf{x})$ is approximating $f(\mathbf{x})$ in the mean squares sense with arbitrary given accuracy $\varepsilon$.

Let us form a regression model, i.e. regression hypothesis as a linear combination of "sufficiently" large number of members of the series $\left[\varphi_{n}(\mathbf{x})\right]$, i.e., define

$\breve{\chi}(\mathbf{x} ; \boldsymbol{\theta})=\sum_{j=0}^{n} \theta_{j} \varphi_{j}(\mathbf{x})$

Then let us find the estimate of vector $\boldsymbol{\theta}^{*}$ using the mean squares method, i.e. find vector $\hat{\boldsymbol{\theta}}$, minimising the function $Q(\boldsymbol{\theta})$, defined by (5).

In order to calculate $\hat{\boldsymbol{\theta}}$ using the operations of linear algebra, there must be a guarantee that the rank $R(\mathbf{F})$ of the matrix $\mathbf{F}=\left(f_{i j}\right)$, where $f_{i j}=\varphi_{j}\left(\mathbf{x}^{i}\right)$, is equal to $n+1$. Although the functions $f_{0:} f_{1}, \ldots, f_{n}$ form a linearly independent system of functions in $D=[a, b]$ and the number of observation points $x^{i}$ usually is much larger than dimension $n+1$ of $\theta$, it may prove that the condition $R(\mathbf{F})=n+1$ is not met. This can be demonstrated by the elementary example where $f_{0}(x)=1, f_{1}(x)=|\cos x|, f_{2}(x)=\sin x$, are functions defined in segment $x \in[0 ; \pi]$.

It is easy to ascertain that such a rank problem of matrix $\mathbf{F}$ does not occur if the model of the linear regression is formed as

$\sum_{j=0}^{n} \theta_{j} \varphi_{j}(x)$

where $\varphi_{j}(x)$ is Legendre, resp. Jacobi, resp. Chebyshev orthogonal polynomials.

If the number of members of our regression model is too large, then the last components of vector $\hat{\boldsymbol{\theta}}$ will be very small. By estimating the influence of $\theta_{n} f_{n}(\mathbf{x})$, it may be concluded that the accuracy of the model is sufficiently high and the last member or several last members should be eliminated. That is especially true for Fourier series where the sin and cos functions are used as basis functions. If the influence of last components of $\hat{\theta}$ is relatively strong, the number of members of the regression model should be increased.

Image transformation. Without limiting the generality of $\mathrm{RM}$ it may be assumed that digital images of all analysed scenes are given with matrices of fixed size, i.e. $\mathbf{A}=\mathbf{A}_{m, n}$. Let us relate the image with the rectangle $P$ in the first quadrant of the xoy plane extending $n-1$ units on the $x$ axis and $m-1$ units on the $y$ axis.

Let us assume that the continuous geometric surface exists, analytically described within the rectangle $P$ by function $z=z(x, y)$ with property $z(i, j) \approx a_{i j}$. More precisely, $a_{i j}$ is the sample taken from the universe represented by the random variable $X_{i j}=z(i, j)+X$, where $X$ is a random variable with the mean value $E X=0$ and variance $D X=\sigma^{2}$. A wellgrounded assumption is that $\sigma^{2}$ is rather small and, therefore, $z(i, j) \approx a_{i j}$.

If we choose an appropriate set of basis functions $\left\{f_{0}(x, y)\right.$, $\left.f_{1}(x, y), \ldots, f_{K}(x, y)\right\}$ defined in rectangle $P$ so that its elements form a linearly independent system of functions, then the unknown value $z(x, y), \quad(x, y) \in P$, may be expressed as a linear combination of functions $f_{k}(x, y)$ with appropriate coefficients $\theta_{k}^{\prime}$, i.e. $z(x, y)$ can be well approximated by the expression

$\sum_{k=0}^{K} \theta_{k}^{\prime} f_{k}(x, y)$

Unknown coefficients $\theta_{k}^{\prime}$ ensuring the „sufficiently good” approximation of $z(x, y)$ can be estimated on the basis of the least squares method using the elements $a_{i j}$ of the matrix $\mathbf{A}_{m, n}$. Such an approach leads to the following algorithm for the calculation of estimated values $\hat{\theta}_{k}$ of coefficients $\theta_{k}^{\prime}$. Let us define the matrix

$\mathbf{F}_{m n, K+1}=\left(f_{s k}\right)$, 
where $\left(f_{s 0}, f_{s 1}, \ldots, f_{s K}\right)=\left(f_{0}(i, j), f_{1}(i, j), \ldots, f_{K}(i, j)\right)$ and $s=i n+j$. If $m n>>+1$, we will obtain the non-singular matrix

$\mathbf{M}=\mathbf{F}^{T} \mathbf{F}$

with dimensions $(K+1) \times(K+1)$, where $T$ denotes a transpose operation. As the matrix $\mathbf{M}$ is not singular, the inverse matrix $\mathbf{M}^{-1}$ exists. By enumeration of elements $a_{i j}$ of matrix $\mathbf{A}_{m, n}$ in the same sequence as values of basic functions, we obtain the column vector of size $m \times n$ :

$\mathbf{a}=\left(a_{1}, a_{2}, \ldots, a_{m n}\right)^{T}$.

The sought estimate $\hat{\boldsymbol{\theta}}$ of the vector $\boldsymbol{\theta}^{\prime}$ is calculated using the following formula:

$\hat{\boldsymbol{\theta}}=\mathbf{M}^{-1} \mathbf{F}^{T} \mathbf{a}$.

As the digital image of the scene quite often is a matrix with rather large dimensions, practical implementation of the RM usually is based on fragmentation of $\mathbf{A}_{m, n}$ into sub-matrices of smaller size. When the fragmentation is applied, care should be taken to ensure that the size of the feature set of the scene does not exceed the size of the sub-matrix. Let us assume for now that the values of $m$ and $n$ are not large and can be practically used for implementation of the first stage of the regression method, i.e. estimation of vectors of regression coefficients $\hat{\boldsymbol{\theta}}$. Using the sets of available digital images $S_{1}, S_{2}, \ldots, S_{a}$ related to classes $K_{1}, K_{2}, \ldots, K_{a}$ of scenes under investigation, we calculate the sets of vector estimates $T_{1}, T_{2}, \ldots, T_{a}$. Obviously the cardinality of sets $S_{i}$ and $T_{i}$ is equal. It is preferable that the sets are sufficiently large.

Clustering of the vector sets of regression coefficients. In fact, by transformation of the digital images $\mathbf{A}=\left(a_{i j}\right)$ to the vectors of coefficients $\hat{\boldsymbol{\theta}}$ of the linear regression model we perform reduction of the dimensions of primary feature vectors or matrixes $\mathbf{A}$. The dimension of primary feature vectors (product of the number of rows and columns in matrix A) may exceed 400 , but the dimension of vectors $\hat{\theta}$ in the case of the adequate regression model will rarely exceed 25 . Obviously, if $R(\mathbf{F})=n+1$, then the matrix $\mathbf{M}=\mathbf{F}^{T} \mathbf{F}$ shall not be singular and its inverse matrix $\mathbf{M}^{-1}$ shall exist. In this case, calculation of vectors $\hat{\boldsymbol{\theta}}$ for all digital images $\mathbf{A}$ is performed using the formula $\hat{\boldsymbol{\theta}}=\mathbf{M}^{-1} \mathbf{F}^{T} \mathbf{y}$, where $\mathbf{y}$ is the layout of elements $a_{i j}$ of matrix $\mathbf{A}$ in one column. Therefore, the transformation process is performed relatively fast.

However, the multiplicity of geometric forms and placements of the foreign object to be identified leads to the need of further reduction of amount of information processed for taking the final decision. Therefore, the set of vectors $\hat{\theta}$ related to one category of images should be clusterised and each cluster should be represented by the vector of the cluster centre. Decision of the identification then will be made on the basis of a really small number of feature vectors 5,7 or 9 . To ensure proper "quality" of distribution of the set of vectors $\hat{\boldsymbol{\theta}}$ into the clusters and consequently, forming a "qualitative" system of cluster centres, the clustering pro- cedure itself should be carefully planned. For this reason, the metric most relevant to the character of the recognition problem should be chosen from the different: Euclidian, weighed Euclidian, Jordan's (Chebyshev's), city block metrics (Marques de Sá, 2001).

More distance metrics are possible that meet the axioms of metric spaces, namely identity axiom, symmetry axiom and triangle axiom. On the basis of the chosen measure of distance, it is possible to define the similarity or closeness measure $s\left(\hat{\boldsymbol{\theta}}_{1}, \hat{\boldsymbol{\theta}}_{2}\right)$ of two vectors, e.g.

$s\left(\hat{\boldsymbol{\theta}}_{1}, \hat{\boldsymbol{\theta}}_{2}\right)=e^{-d\left(\hat{\boldsymbol{\theta}}_{1}, \hat{\boldsymbol{\theta}}_{2}\right)}$

where $d\left(\hat{\boldsymbol{\theta}}_{1}, \hat{\boldsymbol{\theta}}_{2}\right)$ is the chosen distance measure (Tou, 1974).

Obviously, the inequality $0 \leq s\left(\hat{\boldsymbol{\theta}}_{1}, \hat{\boldsymbol{\theta}}_{2}\right) \leq 1$ will hold.

Similarity measure $s\left(\hat{\boldsymbol{\theta}}_{1}, \hat{\boldsymbol{\theta}}_{2}\right)$ may be defined also in a different way, independently of a distance measure. For example, it can be defined by the expression

$$
s\left(\hat{\boldsymbol{\theta}}_{1}, \hat{\boldsymbol{\theta}}_{2}\right)=\frac{1}{2}\left(\frac{\sum_{k=0}^{K} \hat{\theta}_{1, k} \cdot \hat{\theta}_{2, k}}{\sqrt{\sum_{k=0}^{K}\left(\hat{\theta}_{1, k}\right)^{2}} \cdot \sqrt{\sum_{k=0}^{K}\left(\hat{\theta}_{2, k}\right)^{2}}}+1\right) \text {. }
$$

The distance measure between the clusters $C$ and $C^{\prime}$ should be chosen after that. The most popular are:

$D_{m}\left(C, C^{\prime}\right)=\frac{1}{|C|\left|C^{\prime}\right|} \sum_{(\mathbf{x}, \mathbf{y}) \in C \times C^{\prime}} d(\mathbf{x}, \mathbf{y}) ;$

$D_{c}\left(C, C^{\prime}\right)=d(\overline{\mathbf{x}}, \overline{\mathbf{y}})$

$D_{\min }\left(C, C^{\prime}\right)=\min _{(\mathbf{x}, \mathbf{y}) \in C \times C^{\prime}} d(\mathbf{x}, \mathbf{y})$;

$D_{\max }\left(C, C^{\prime}\right)=\max _{(\mathbf{x}, \mathbf{y}) \in C \times C^{\prime}} d(\mathbf{x}, \mathbf{y})$,

where $\overline{\mathbf{x}}=\frac{1}{|C|} \sum_{\mathbf{x} \in C} \mathbf{x}, \overline{\mathbf{y}}=\frac{1}{\left|C^{\prime}\right|} \sum_{\mathbf{y} \in C^{\prime}} \mathbf{y}$.

Obviously, each of these cluster distances is determined by the choice of $d(\mathbf{x}, \mathbf{y})$, i.e., choice of the used metric. We can use at least 16 different cluster distances. Consequently, the number of possible clustering procedures will exceed 160 .

From these, agglomerative hierarchic clustering (Tou, 1974; Marques de Sá, 2001) procedures using the complete linkage (distal neighbour) principle, i.e. taking the $D_{\max }$ as a cluster distance measure, are rather effective and fast. However, it would be unsound to conclude that only procedures of this type should be used to perform "qualitative" clustering.

One of the most appropriate clustering methods, preferred also here, is the agglomerative hierarchic clustering. Its implementation in any case is based on assumption that, initially, each element (vector) of each set $T_{i}$ forms one cluster. To perform the following steps of clustering, it is necessary to define the distance measure between any two clusters. The similarity measure can be also used instead. 
The only difference (at least for traditional cases) will be that, in the case of using distance measure, the closest clusters will be merged, but in the case of using similarity measure, the most similar clusters will be merged.

The distance measure $D_{m}\left(C, C^{\prime}\right)$ is typically used in these procedures, however, with respect to the character of the problem under investigation, one of the measures $D_{c}\left(C, C^{\prime}\right)$, $D_{\min }\left(C, C^{\prime}\right), D_{\max }\left(C, C^{\prime}\right)$ can be used.

If the $v$-th step of hierarchic clustering has produced clusters: $C_{1}, C_{2}, \ldots, C_{k_{v}}$, then the $(v+1)$-th step results in merging of two closest of them (according to the chosen distance measure). The researcher should choose the criterion for stopping the clustering process relevant for the particular classification task.

A potentially large cluster size may render their direct application impractical. Therefore, the proposed approach recommends to replace the resulting clusters by their centres, i.e. vectors defined in a special way. The simplest case is when the centre $\mathbf{x}_{C}$ of cluster $C$ is defined by the expression

$\mathbf{x}_{C}=\frac{1}{|C|} \sum_{\mathbf{x} \in C} \mathbf{x}$

For the following analysis the cluster is represented by its centre.

Classification of images. If the digital images of scenes under investigation are matrices of rather small dimensions, their fragmentation for forming classification rules is not necessary. In a dichotomic situation, when all digital images are to be divided into two categories, namely, images representing real scenes with and without foreign objects, there could be different rationally justified decision rules. If we denote by $\mathbf{z}_{11}, \mathbf{z}_{12}, \ldots, \mathbf{z}_{1 K_{1}}$ the cluster centres of the first category of feature vectors $\hat{\boldsymbol{\theta}}$ and by $\mathbf{z}_{21}, \mathbf{z}_{22}, \ldots, \mathbf{z}_{2 K_{2}}$ the centres of the second category, then the decision rule $R_{1}$ can be formulated as follows: the analysed digital image $\mathbf{A}$ is transformed into the feature vector $\hat{\boldsymbol{\theta}}$ and distances $d\left(\hat{\boldsymbol{\theta}}, \mathbf{z}_{1 i}\right)$ and $d\left(\hat{\boldsymbol{\theta}}, \mathbf{z}_{2 j}\right)$ are calculated, where $i=\overline{1, K_{1}}$ and $j=\overline{1, K_{2}}$. A is classified as the image of the first category if

$\min _{i=1, K_{1}} d\left(\hat{\boldsymbol{\theta}}, \mathbf{z}_{1 i}\right) \leq \min _{j=1, K_{2}} d\left(\hat{\boldsymbol{\theta}}, \mathbf{z}_{2 j}\right)$

or of the second category otherwise. Obviously, this decision rule directly depends on the choice of $d(\cdot)$. Hence it has at least four versions.

Decision rule $R_{2}$ is formulated as follows: vector of reduced features $\hat{\boldsymbol{\theta}}$ is used to calculate distances $d\left(\hat{\boldsymbol{\theta}}, \mathbf{z}_{1 i}\right)$ and $d\left(\hat{\boldsymbol{\theta}}, \mathbf{z}_{2 j}\right)$ as described above. After that, three (resp. 5 or 7) smallest distances are chosen and $\mathbf{A}$ is classified as the image of the first category if more than a half of the chosen distances belong to the set $\left\{d\left(\hat{\boldsymbol{\theta}}, \mathbf{z}_{11}\right), d\left(\hat{\boldsymbol{\theta}}, \mathbf{z}_{12}\right), \ldots, d\left(\hat{\boldsymbol{\theta}}, \mathbf{z}_{1 K_{1}}\right)\right\}$, or of the second category otherwise. The possible number of versions for the rule $R_{2}$ will be more than or equal to 12 .
Rule $R_{3}$ differs from rule $R_{1}$ in that the decision to classify A as the image of the first category is made if $\frac{1}{K_{1}} \sum_{i=1}^{K_{1}} d\left(\hat{\boldsymbol{\theta}}, \mathbf{z}_{1 i}\right) \leq \frac{1}{K_{2}} \sum_{j=1}^{K_{2}} d\left(\hat{\boldsymbol{\theta}}, \mathbf{z}_{2 j}\right)$.

If the dimensions of images under investigation are too large, fragmentation of matrices $\mathbf{A}_{m, n}$ is performed first into matrices of sufficiently small and fixed dimensions. In this case, rules $R_{s}, s=\overline{1,3}$, defined above, are applied to sub-matrices of full digital images. After that, a classification rule $R^{*}$ for the entire images is formed, using the ,voting” principle. If the majority of $N$ fragments $\mathbf{A}_{m^{\prime}, n^{\prime}}$ of the full image $\mathbf{A}_{m, n}$ were classified as related to the first category, then the whole image is classified as related to this first category. Such "voting" in systems for medical diagnostics might be too trivial to provide effective classification; suitable solution could be based on application of weighing coefficients for the "votes" of each category. In the case of two classes only, this leads to selection of the threshold $\Delta$ such that $R^{*}\left(\mathbf{A}_{m, n}\right)=1$ if and only if the number of fragments, for which the $R^{*}\left(\mathbf{A}_{m^{\prime}, n^{\prime}}\right)=1$, exceeds $\Delta$.

\section{RESULTS}

The proposed methods were developed and successfully used in the European FP6 project MODULINSPEX for detection of small foreign objects in food products by processing their X-ray images in real time mode. Three different approaches to detection of small objects on the background clutter were proposed, with different levels of complexity and different application scope. The obtained results are presented below.

For the considered application task related with finding contamination objects in meat, 1D median subtraction filtering was used in the preprocessing stage to obtain an image where the background is eliminated. Figure 1 illustrates the initial image and results obtained on the basis of such an approach. Two 1D filtering operations instead of one 2D filtering were used to save processing time (for the particular application, 2D filtering does not provide significant result enhancement). Length $M$ (in pixels) of the median filter has to exceed doubled maximum size $d$ of the objects to be detected $(M>2 d)$ to extract such objects from the background.

Implementation of the thresholding method with connectivity analysis was performed taking into account that the shape of the sought object may vary and there was only a need to filter out accidental noise from the binary images obtained after thresholding. Therefore, SE of size $2 \times 2$ pixels containing all 1's was applied and positive decision about the presence of the sought object was made if values of at least 3 pixels within the particular neighbourhood of the binary image were equal to 1 . Figure 2 illustrates this approach applied to the filtered image that was shown in Figure 1b. It may be noticed that pixels related to noise in 
(a)

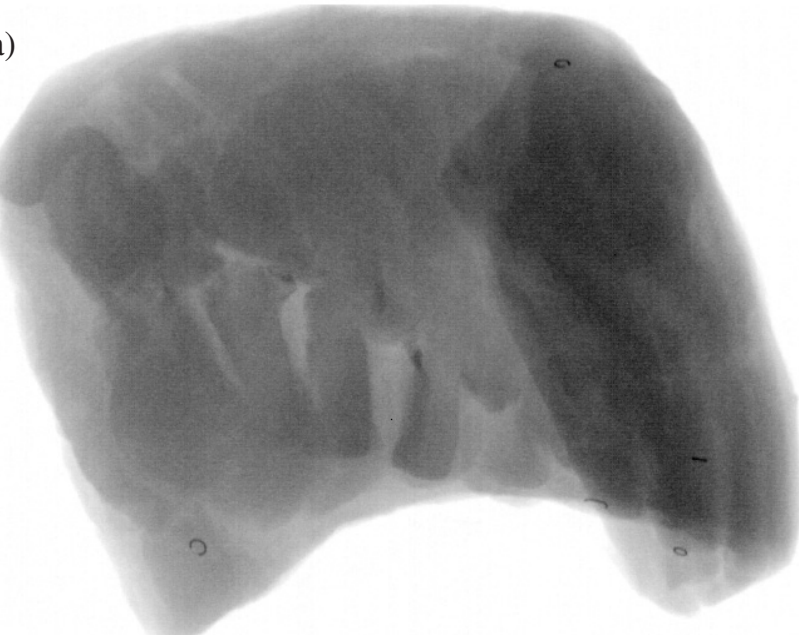

(b)

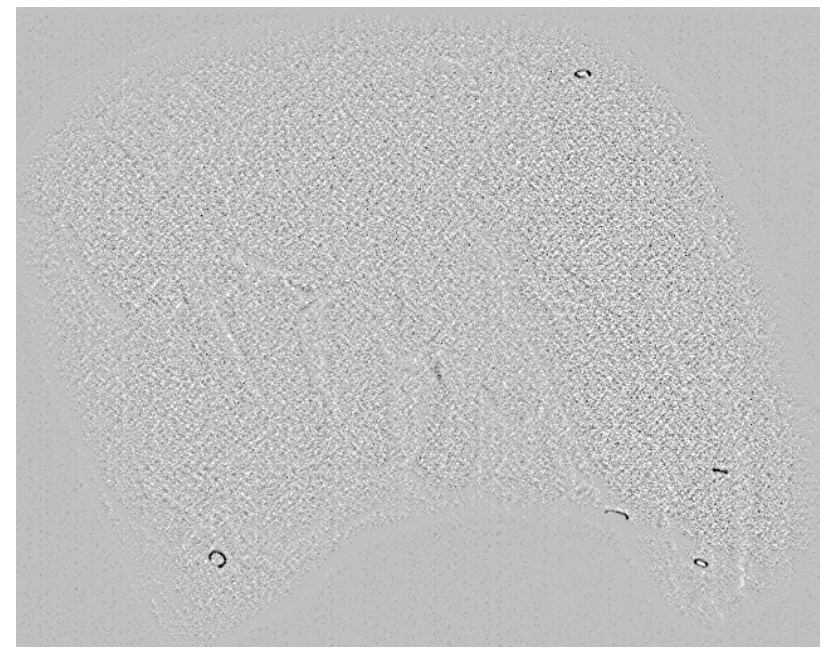

Fig. 1. Extraction of small objects from a changing background: (a) initial image; (b) filtered image.

(a)

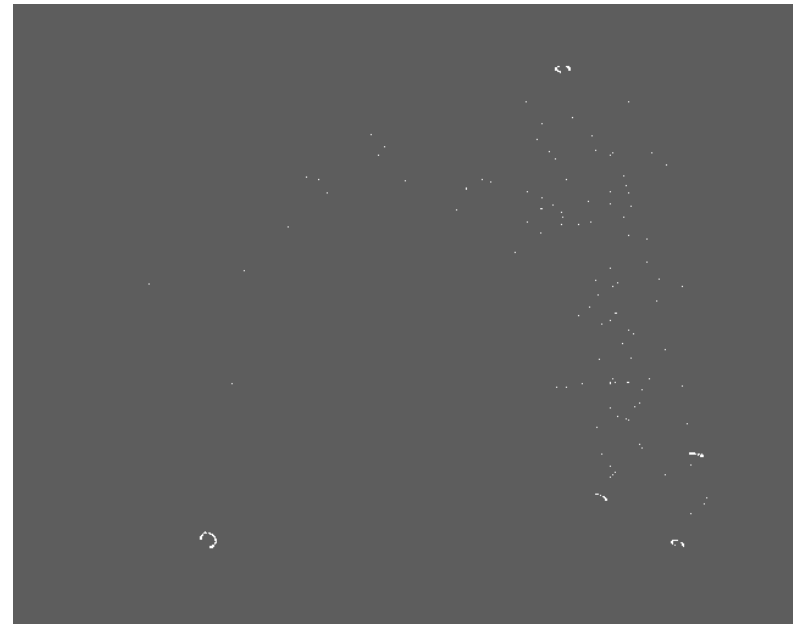

(c)

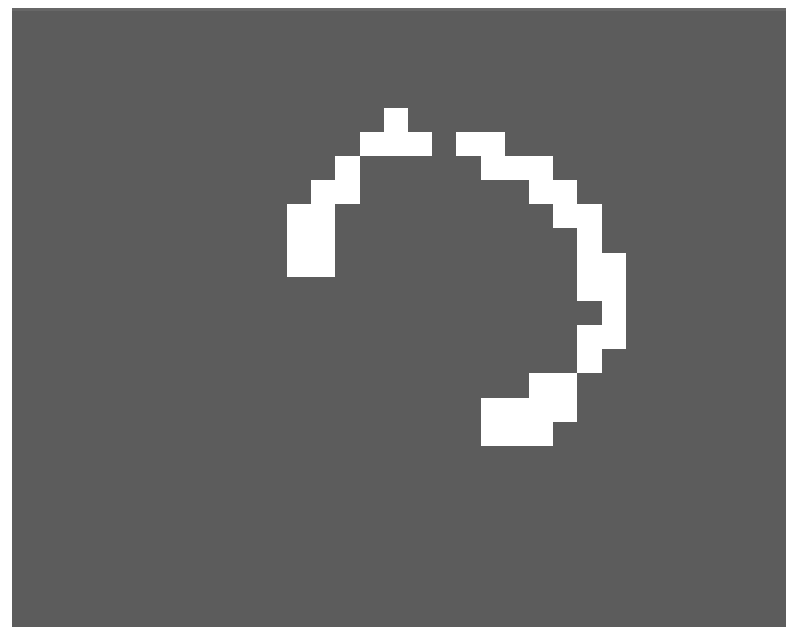

(b)

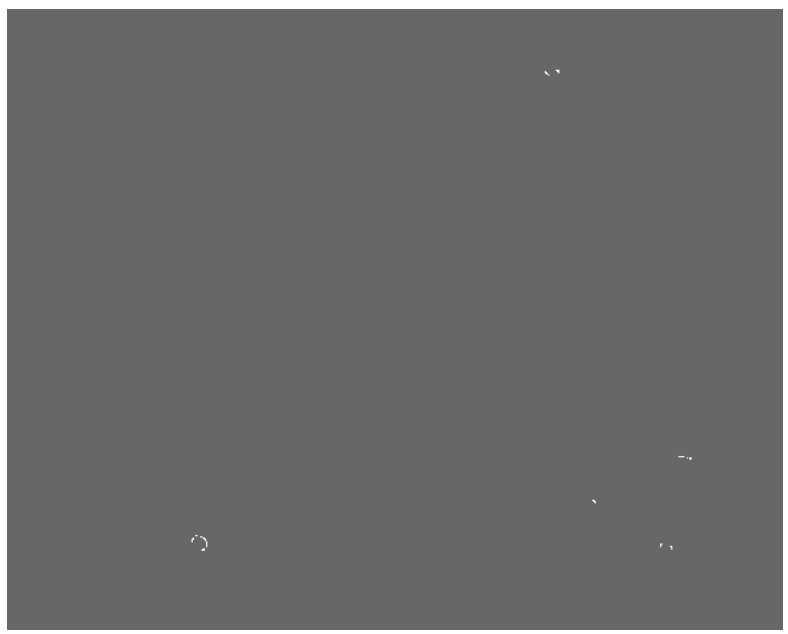

(d)

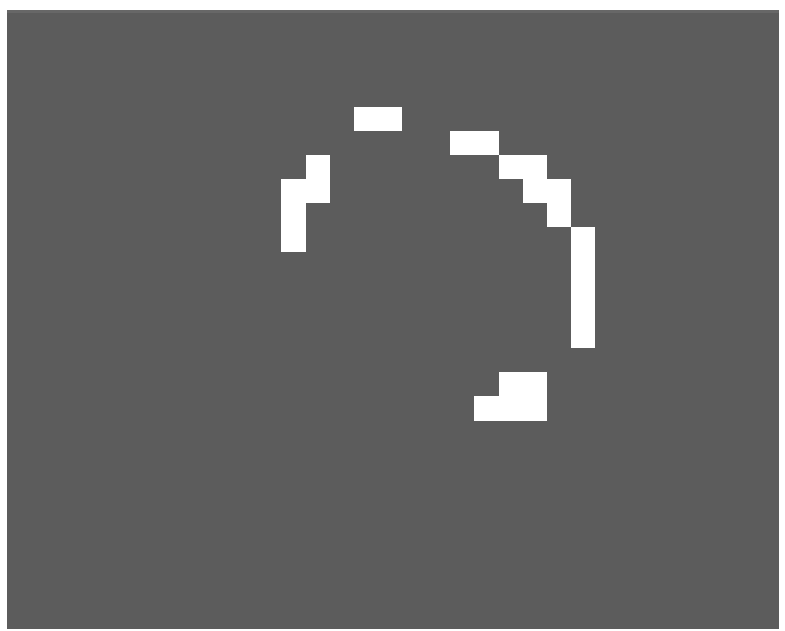

Fig. 2. Results of thresholding with connectivity analysis: (a) thresholded image; (b) image after the connectivity analysis; (c) zoomed-in fragment of (a); (d) zoomed-in fragment of (b).

binary image were successfully removed and only those related to real objects were left.

Figure 3 illustrates the sample results obtained using the proposed object detection method based on calculation of covariance properties. Figure 3 a shows a fish fillet image after filtering of the background, the profile of the marked line is shown on Figure $3 \mathrm{~b}$. It is seen from the line profile that the noise is masking the presence of the fishbone in the image. Coefficients $C_{Q}^{1}$ calculated for all image fragments with size $8 \times 8$ pixels and overlapping by 4 pixels were stored in a matrix illustrated as a covariance image related to the initial one and shown in Figure $3 \mathrm{c}$. It is seen that val- 
(a)

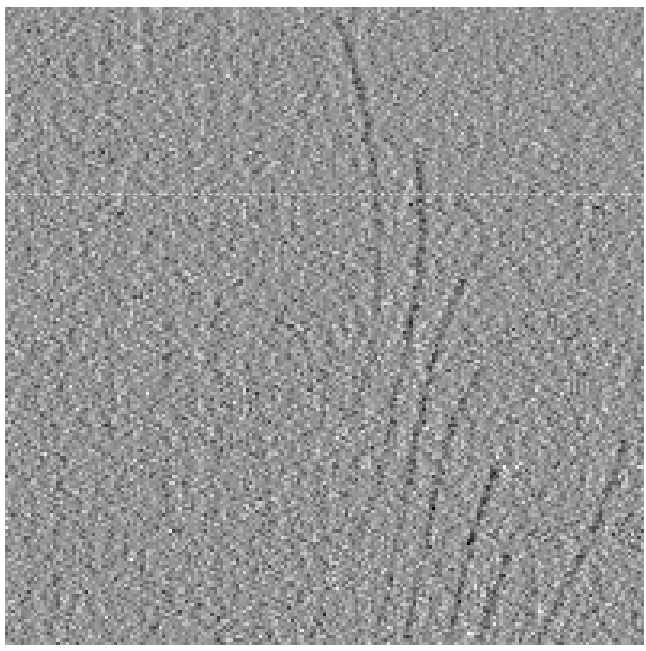

(c)

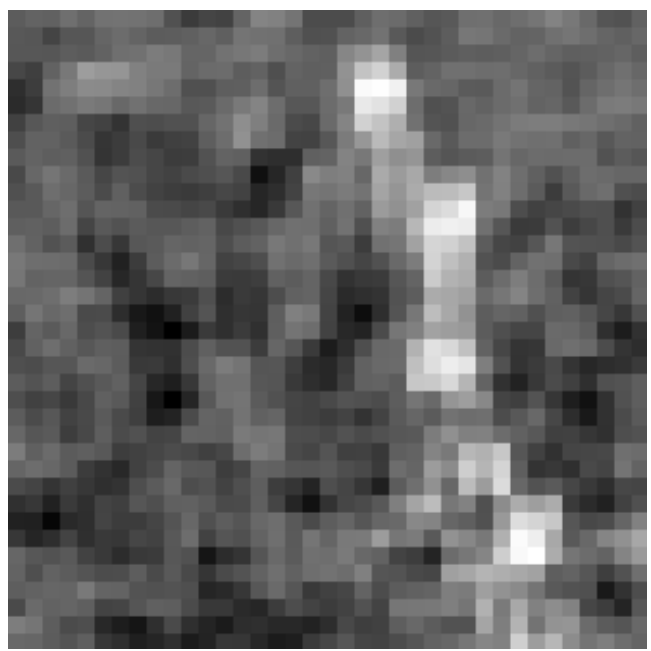

(b)

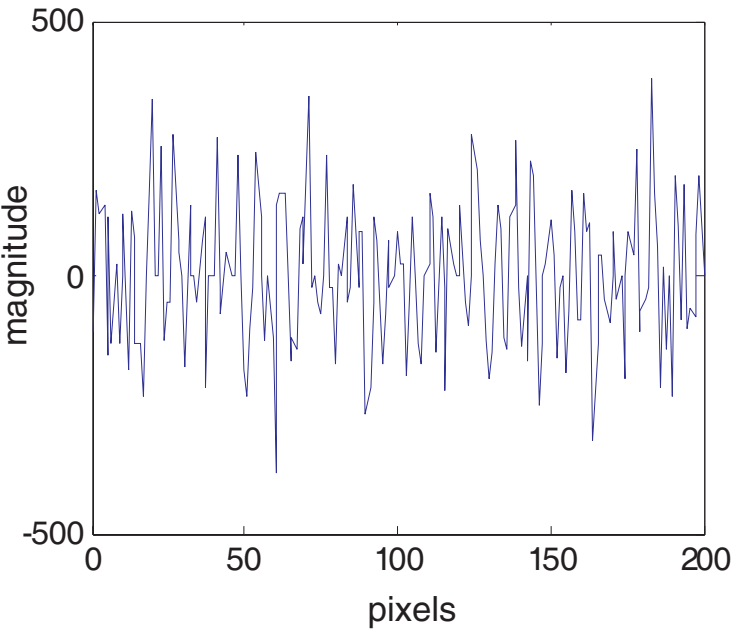

(d)

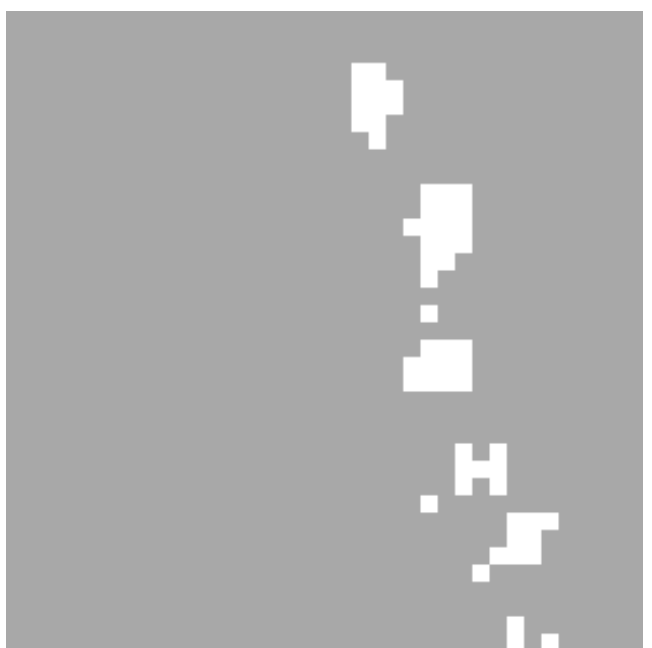

Fig. 3. Detection of fishbones: (a) fragment of the filtered image with fishbones; (b) profile of the line marked in (a); (c) image of covariance coefficients ; (d) thresholded image of covariance coefficients.

a)

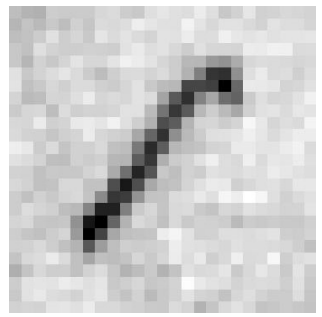

b)

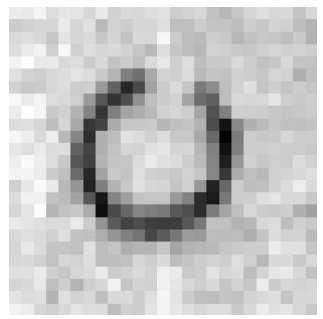

c)

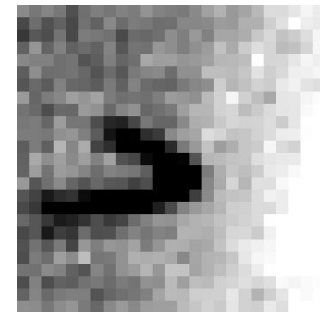

d)

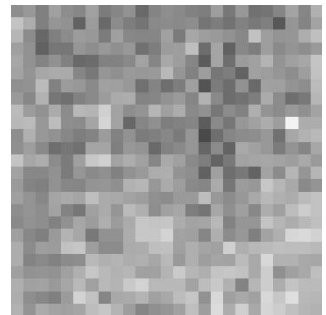

Fig. 4. a), b), c), fragments with a foreign object; d) "normal" fragment.

ues of coefficients $C_{O}^{1}$ are higher for fragments containing vertical segments of fishbones. Thresholding of the covariance image was used to separate fragments containing fishbones and results are shown in Figure 3d. It may be noticed that calculation of covariance based property has provided means for detection of image fragments containing vertical fishbones.

The proposed regression method was validated against the object detection task illustrated in Figure 1. The set of basis functions contained 25 members; dimensions of the analysed image fragments were $25 \times 25$ pixels; distances be- tween the vectors of regression coefficients were calculated using the Jordan's (Chebyshev) metric. Agglomerative hierarchic clustering method (Tou, 1974; Marques de Sá, 2001) was used for clustering of vectors of regression coefficients. The solved task is illustrated in Figure 4. In Figure 4a, b, c, a sample fragment containing a foreign object is depicted; Figure 4d shows the 'normal' fragment. Thirty-five fragments containing a foreign object and 75 'normal' fragments were used for clustering resulting in 7 and 5 clusters correspondingly. 100 fragments from images of meat samples were processed; then they were classified by calculating distances to the centres of these clusters. As a result, all 
fragments were classified properly as containing or not containing a foreign object.

\section{DISCUSSION}

Proposed object detection methods have been developed and successfully used for processing of images related to real application tasks. They form a set of tools that can be used to solve object detection or image classification tasks in various application areas. All described methods are useable in computer systems operating in real time mode and provide means to adjust them to the particular application task.

The proposed regression method (RM) of pattern recognition is not qualified as fully novel. The elements of the approach are found e.g. in (Лоренц, 1984; 1989; Marques de Sá, 2001). Its first principles are given in publications (Лоренц, 1984; 1989) and even in a more generic form in (Marques de Sá, 2001). There are differences also related to mathematical correctness. In addition, the proposed method is tightly coupled with the set of clustering techniques. As a result, the proposed RM has the following degrees of freedom:

- Selection of the appropriate system of basis functions

- Selection of fragmentation size of the full digital image of the scene under investigation

- Selection of metric for calculation of distance (resp. similarity measure) in the vector space of linear regression coefficients

- Selection of metric for calculation of distance (resp. similarity) between the clusters

- Selection of procedure for clustering of the set of coefficient vectors

- Selection of procedure of forming the cluster centres

- Selection of classification rules of digital images
The mathematical approach of this method is generic and exposes features that bring it close to problems not only related with industrial inspection but e.g. faced in biomedical image processing and other areas. It is proposed for solving image classification tasks in computer systems based on processing of digital images regardless of the technology used to obtain them.

\section{REFERENCES}

Armitage, P., Berry, G., Matthews, J.N.S. (2001). Statistical Methods in Medical Research. New York: Wiley-Blackwell. 832 pp.

Deshpande, S.D., Er, M.H., Ronda, V., Chan, P. (1999). Max-Mean and Max-Median filters for detection of small-targets. In: Signal and Data Processing of Small Targets (pp. 74-83). SPIE Proceedings series, Vol. 3809.

Fukunaga, K. (1990). Introduction to Statistical Pattern Recognition. 2nd edn. New York: Academic Press. 591 pp.

Liu, Z., Shen, X., Sang, H. (2005). A Learning-Based Spatial Processing Method for the Detection of Point Targets. In: Lecture Notes in Computer Science (pp. 1043-1050). Vol. 3930/2006, ICMLC 2005. Springer.

Marques de Sá, J. P. (2001). Pattern Recognition: Concepts, Methods and Applications. Portugal: Springer. 318 pp.

Pratt, W.K. (2001). Digital Image Processing. New York: John Wiley \& Sons. $735 \mathrm{pp}$.

Tou, J.T., Gonzales, R.C. (1974). Pattern Recognition Principles. London; Amsterdam: Addison-Wesley. 377 pp.

Warren, R.C. (2002). The Performance of Small Support Spatial and Temporal Filters for Dim Point Target Detection in IR Image Sequences. DSTO-TR-1282, http://www.dsto.defence.gov.au/corporate/reports/ DSTO-TR-1282.pdf

Бахвалов Н.С. (2001). Численные методы [Numerical Methods]. Санкт-Петербург, 632 с. (in Russian).

Курант Р., Гильберт Д. (1951). Методы математической физики. Т. 1 [Methods of Mathematical Physics]. Москва, 477 c. (in Russian).

Лоренц А. (1984). Регрессионый анализ и распознавание образов [Regression analysis and pattern recognition]. В кн.: Автоматизация анализа и распознавания изображений. Ч. 4. (с. 5-25). Рига: Институт электроники и вычислительной техники (in Russian).

Лоренц А. (1989). Статистические свойства интегрального метода эталонов [Statistical features of the integral method of prototypes]. В кн.: Четвертая Всесоюзная конферениия «Математические методы распознавания образов», Рига. (с. 53-64). Рига (in Russian).

Received 4 December 2008

\section{ĀTRA OBJEKTU ATKLĀŠANA DISKRĒTOS PELĒKO TOṆU ATTĒLOS}

Darbā aplūkotas specifisku objektu atklāšanas problēmas digitālos pelēko toṇu attēlos sekojošos apstākḷos: iespējams analizēt relatīvi mazus attēla fragmentus (ir pieejama iepriekšēja informācija par meklējamo objektu izmēriem); attēli satur nedefinētu lielāku objektu fonu; nepieciešams minimizēt apstrādes laiku, tam jābūt neatkarīgam no attēla satura; jāizstrādā metodes, kuras var efektīvi realizēt, izmantojot specializētas mikroshēmas. Pēdējie divi nosacījumi izriet no mērḳa piedāvāt pieejas, kuras var izmantot reālā laika sistēmās apstākḷos, kad zināmas sarežğìtas attēlu apstrādes metodes nav izmantojamas nepietiekošu pieejamo resursu dēḷ. Darbu motivēja potenciālie pielietojumi pārtikas rūpniecībā (svešḳermeṇu atklāšana produktos, apstrādājot to rentgena attēlus), medicīnā (anomāliju atklāšana datortomogrāfu attēlos u.c.). Risināmie uzdevumi ietver kompaktu mazu objektu, dažādos virzienos liektu līniju, mazu attēla rajonu atklāšanu ar gaišumu, kas atšḳiras no fona, un tamlīdzīgi. Darbā aprakstītas piedāvātās attēlu apstrādes pieejas šādu objektu atrašanai, kā arī ilustrēti rezultāti, kuri iegūti, apstrādājot pārtikas preču paraugu attēlus. 